recruitment to clinical trials. Pulmonary and Activation-Regulated Chemokine (PARC/CCL18) is a plausible biomarker based on previous reports in other respiratory diseases, making it worthy of study in COPD.

Methods PARC was measured using ELISA in serum samples from 115 patients enrolled in The London COPD cohort, including 44 paired samples taken at baseline and exacerbation (pre-treatment). PARC was assessed with relation to exacerbation frequency and other inflammatory markers.

Results The study cohort comprised of 77 males, 34 current smokers, mean age 69.6 years (SD 9.1), $\mathrm{FEV}_{1} 1.13$ (0.47) 1 (45.3 (18.0)\% predicted), baseline PARC concentration $124 \mathrm{ng} / \mathrm{ml}$ (40.4), median (IOR) exacerbation frequency 1.8/year (0.6-3.0). Higher PARC concentration was associated with more frequent exacerbations $(\mathrm{r}=0.22, \mathrm{p}=0.035)$. PARC was not related to age, sex, BMI, disease severity $\left(\mathrm{FEV}_{1}\right)$, or smoking pack years (all $\mathrm{p}>0.05$ ). Significantly lower PARC concentrations were found in current smokers compared to ex-smokers, $112 \mathrm{ng} / \mathrm{ml}$ vs $130 \mathrm{ng} / \mathrm{ml}$ respectively ( $\mathrm{p}=0.036$ ). PARC did not change from baseline to exacerbation $(131 \mathrm{ng} / \mathrm{ml} \mathrm{vs}$ $125 \mathrm{ng} / \mathrm{ml}, \mathrm{p}=0.256$ ), and the correlation between PARC in the two states was highly significant $(\mathrm{r}=0.53, \mathrm{p}<0.0001)$. PARC was related to baseline CRP $(r=0.28, p=0.013)$ and blood eosinophil count $(r=0.39, p=0.001)$, with no significant associations at exacerbation, and no relationship with neutrophils or total white blood cell count.

Conclusion A relationship has been demonstrated between serum PARC concentration and exacerbation frequency in patients with COPD. Correlations between PARC, eosinophils and CRP indicate that this biomarker may identify a subset of patients with a particular inflammatory profile, suggesting specific treatment options. Further work should be carried out to explore the relevance of PARC as a biomarker in the COPD population.

\section{P117 COMPARISON OF INDICES OF NUTRITIONAL STATUS IN PREDICTION OF IN-HOSPITAL MORTALITY AND EARLY READMISSION OF PATIENTS WITH ACUTE EXACERBATIONS OF COPD}

doi:10.1136/thx.2010.150987.18

1J Steer, ${ }^{1} E$ Norman, ${ }^{2} \mathrm{G}$ J Gibson, ${ }^{1} \mathrm{~S}$ C Bourke. ${ }^{1}$ North Tyneside General Hospital, North Shields, Tyne and Wear, UK; ${ }^{2}$ Institute of Cellular Medicine, Newcastle University, Newcastle-upon-Tyne, UK

Introduction and objectives In patients hospitalised with an acute exacerbation of COPD (AECOPD), low body mass index (BMI) predicts in-hospital death. The Malnutrition Universal Screening Tool (MUST) incorporates BMI and patient-reported weight loss over the previous 6 months to provide an overall assessment of malnutrition risk. It predicts mortality in elderly hospitalised patients ${ }^{1}$ but, to our knowledge, the prognostic value of this tool in AECOPD has not been previously reported.

Methods We prospectively identified patients hospitalised with AECOPD. We investigated the ability of BMI, self-reported weight loss and MUST score to predict in-hospital mortality and 28-day readmission. BMI $<18.5 \mathrm{kgm}^{-2}$ was considered underweight (World Health Organisation, 2004). Odds Ratios (OR) were calculated using normal BMI, weight loss $<5 \%$, and MUST score 0 as reference values. Results 608 patients were included; mean (SD) age 72.8 (10.2) years, $55.8 \%$ female, mean (SD) $\mathrm{FEV}_{1}$ (if performed within 2 years of admission, $n=398) 43.5$ (18) \% predicted. 61 (10\%) patients died inhospital $(6.9 \%$ in those with simple exacerbations, $16.5 \%$ in exacerbations associated with pneumonia). Of patients surviving to discharge, 95 (17.4\%) were readmitted within 28 days (Abstract P117 Table 1). In-hospital mortality was predicted by BMI $<18.5 \mathrm{kgm}^{-2}$ (OR 2.5, 95\% CI 1.27 to $4.91, \mathrm{p}=0.008$ ) whereas weight loss $>10 \%$ predicted early readmission (OR 3.90, 95\% CI 2.09 to $7.28, \mathrm{p}<0.001$ ). A high risk of malnutrition (MUST $\geq 2$ ) was the only measurement that significantly predicted both inhospital mortality (OR 2.10, 95\% CI 1.18 to 3.74, $\mathrm{p}=0.011$ ) and early readmission to hospital (OR 1.71, 95\% CI 1.04 to 2.83, $\mathrm{p}=0.034)$. BMI within the overweight range appeared to be protective against early readmission (OR $0.54,95 \%$ CI 0.29 to 0.99 , $\mathrm{p}=0.046$ ).

Conclusion In patients hospitalised with AECOPD, indices of nutritional status are important predictors of outcome. Of interest, BMI and self-reported weight loss predict different outcome measures (in-hospital death and early readmission respectively). A high risk of malnutrition (MUST score $\geq 2$ ) is potentially a useful predictor of both in-hospital mortality and early hospital readmission and we suggest that it should be assessed routinely.

Abstract P117 Table 1 Nutritional measurements and their relationship to outcome

\begin{tabular}{|c|c|c|c|c|c|c|c|c|c|c|}
\hline & BMI (k & $\left.\operatorname{sm}^{-2}\right)$ & & & Weig & ght loss & & MUS & & \\
\hline & $<18.5$ & $18.5-24.9$ & $25-29.9$ & $>30$ & $<5$ & $5-10$ & $>10$ & 0 & 1 & $\geq 2$ \\
\hline$\%$ & 17.8 & 37.5 & 25 & 19.7 & 79.3 & 11.2 & 9.5 & 64.8 & 10.4 & 24.8 \\
\hline $\begin{array}{l}\text { OR for } \\
\text { in-hospital } \\
\text { mortality }\end{array}$ & $2.50^{*}$ & 1 & 1.03 & 0.89 & 1 & 1.52 & 1.59 & 1 & 1.46 & $2.10^{*}$ \\
\hline $\begin{array}{l}\text { OR for early } \\
\text { readmission }\end{array}$ & 0.86 & 1 & $0.54^{*}$ & 0.80 & 1 & 1.36 & $3.90^{*}$ & 1 & 1.24 & $1.71^{*}$ \\
\hline
\end{tabular}

${ }^{*}$ Significance $<0.05$.

\section{REFERENCE}

1. Henderson S, Moore N, Lee E, Witham MD. Do the malnutrition universal screening tool (MUST) and Birmingham nutrition risk (BNR) score predict mortality in older hospitalised patients? BMC Geriatrics 2008;8

\section{P118 PREDICTING SURVIVAL IN PATIENTS ADMITTED TO HOSPITAL WITH AN ACUTE EXACERBATION OF CHRONIC OBSTRUCTIVE PULMONARY DISEASE (COPD)}

doi:10.1136/thx.2010.150987.19

K Williamson, A Sullivan, N Folland, S Rees, S Gompertz. Queen Elizabeth Hospital, Birmingham, UK

Introduction COPD is the fifth biggest cause of death in the UK. It can be difficult to predict when these patients are coming to the end of their life. There are many clinical tools available to aid prediction of death. ${ }^{12}$ As part of a wider COPD audit we assessed whether one of these could identify which patients admitted with an exacerbation should be referred for specialist palliative care.

Method 50 consecutive patients admitted to an acute hospital with exacerbations of COPD were assessed between August and September 2009. Gold Standards Framework ${ }^{1}$ indicators for organ disease and other general predictors of end-stage illness were recorded. Where available (33/50), we calculated a modified BODE score (without the measure of exercise capacity). At 10 months, we assessed how many patients had survived.

Results $30 \%(15 / 50)$ of the patients had died by 10 months. Median BOD score at admission was five in survivors and in those who had died. The remaining data are summarised in Abstract P118 Table 1. Discussion In our group of patients a modified BODE score was not helpful in predicting outcome at 10 months. Recurrent admissions, oxygen therapy, severe breathlessness/dependence and resistant organisms were more prevalent in the group that died. These data 
are being used in further developments to care pathways within our Trust.

Abstract P118 Table 1 Percentage of patients with each indicator recorded as 'yes' in each group at 10 months

\begin{tabular}{lll}
\hline & Died & Survived \\
\hline Severe disease & $20 \%$ (40\% unknown) & $34 \%$ (6\% unknown) \\
Recurrent admissions & $47 \%$ & $43 \%$ \\
Receiving/awaiting assessment for LTOT & $40 \%$ & $26 \%$ \\
MRC 4 or 5 & $87 \%$ & $60 \%$ \\
Right heart failure & $13 \%$ & $11 \%$ \\
Previous ITU/NIV admission & $40 \%$ & $26 \%$ \\
Anorexia/significant weight loss over last & $7 \%$ & $11 \%$ \\
6 months & & \\
Current/past resistant respiratory organ- & $13 \%$ & $6 \%$ \\
isms & $7 \%$ & $17 \%$ \\
Depression & $0 \%$ & $0 \%$ \\
Albumin $<25 \mathrm{~g} / \mathrm{l}$ & $53 \%$ & $23 \%$ \\
Dependence for most ADLs & & \\
\hline
\end{tabular}

\section{REFERENCES}

1. Gold Standards Framework. Prognostic indicator guidance. 2008. Available at: www. goldstandardsframework.nhs.uk/resources/GOLD\%20standards\%20framework/ PIG paper final (accessed 19 Jul 2010).

2. Celli BR, Cote CG, Marin JM, et al. The body-mass index, airflow obstruction, dyspnoea and exercise capacity index in chronic obstructive pulmonary disease. $N$ Engl J Med 2004;350:1005-12.

\section{P119 COPD ASSESSMENT TEST SCORES: SHORT-TERM CHANGES DURING RECOVERY FROM COPD EXACERBATION}

doi:10.1136/thx.2010.150987.20

S Chandramouli, S Huq, J Lagan, L Davies. University Hospital Aintree, Liverpool, UK

Introduction The COPD assessment test (CAT) is a brief questionnaire that seems to serve as a reliable measure of COPD health status. (1). Little is known about CAT scores in patients in the UK hospitalised with COPD exacerbations and the impact of factors such as age, COPD severity and co-morbidities on CAT scores during recovery.

Aims To record CAT scores in patients hospitalised with COPD exacerbations. To assess the impact of age, $\mathrm{FEV}_{1}$ and co-morbidities on CAT score improvements.

Methods A random selection of patients presenting to our hospital between December 2009 and June 2010 with a clinical diagnosis of COPD exacerbation were approached. Those with radiological or clinical evidence of pneumonia, lung malignancy and bronchiectasis were excluded. All patients had evidence of fixed airflow obstruction on previous spirometry obtained from out-patient clinic visits and were current or ex smokers. Baseline demographics were recorded and patients were asked to complete CAT questionnaires on day 0 (day of hospital admission), day 2 and day 7.Questionnaires were completed at the bedside or, in those discharged, over the telephone. Charlson Comorbidity Indices (CCI) were calculated, using information from hospital case notes.

Results 83 patients (52 female) with a mean (SD) age of 67 (11) years and mean $\mathrm{FEV}_{1}$ of $43 \%$ (18) predicted were recruited. The median (range) CCI score was $4(1-11)$. Mean (SD) CAT scores on days 0,2 and 7 were 30.6 (5.8), 28.3 (6.7) and 26.4 (7.2) units respectively. The difference in scores between days 0 and 2 was -2.4 units (paired t-test, $p<0.0001$ ) and between days 0 and 7 was -4.2 units $(p<0.0001)$. See Abstract P119 Table 1 for correlation co-efficients.
Conclusions Mean CAT scores in this group of hospitalised patients were very high in keeping with our previous studies in similar patients who had high St George's Respiratory Questionnaire scores. (2). CAT scores improve significantly as early as 2 days after treatment for an exacerbation and improve further by day 7 . In our cohort, there was no significant correlation between improvement in CAT scores and age, $\mathrm{FEV}_{1}$ or CCI. Larger studies are needed to examine these relationships in more depth.

\section{Abstract P119 Table 1}

\begin{tabular}{ll}
\hline $\begin{array}{l}\text { Variable (correlated to change between } \\
\text { day } \mathbf{0} \text { and } 7 \text { scores) }\end{array}$ & Spearman's co-efficient (rho) \\
\hline Age (years) & $r=-0.10(p=0.34)$ \\
$\%$ predicted FEV 1 & $r=-0.20(p=0.06)$ \\
Charlson comorbidity index & $r=-0.06(p=0.56)$ \\
\hline
\end{tabular}

\section{REFERENCES}

1. Jones PW, et al. Development and first validation of the COPD Assessment Test. Eur Respir J 2009;34:648-54.

2. Davies L, et al. BMJ 2000;321:1265-8.

\section{P120 OBSERVATIONAL STUDY OF ACUTE ADMISSIONS WITH NON-INFECTIVE ASTHMA AND COPD TO PERTH ROYAL INFIRMARY FOLLOWING THE ERUPTION OF ICELANDIC VOLCANO EYJAFJALLAJOKULL AND SUBSEQUENT ASH CLOUD FORMATION}

doi:10.1136/thx.2010.150987.21

M E M Wilkie, M Anderson, S Schembri. Perth Royal Infirmary, Perth, UK

Introduction and objectives Eyjafjallajokull, a volcano in Iceland erupted on the 20th March 2010 after a prolonged period of seismic activity starting late 2009. Subsequent ash cloud formation on 14 th April caused considerable disruption to Scottish and European airspace. Studies performed in Japan and the British West Indies showed that noxious by-products including sulphur dioxide, have a significant impact on asthma and COPD admissions and severity. ${ }^{12}$ The aim of this study was to record trends of hospitalisation for non-infective exacerbations of asthma and COPD from eruption until volcano quiescence.

Methods Data of all patients admitted to PRI over the period of 20 March 2010 to 31 May 2010 with shortness of breath was collected. Patients included were those with a diagnosis of non-infective asthma or COPD. Other admission diagnoses were excluded. We recorded diagnosis, age and sex.

Results 100 patients were admitted with shortness of breath during the study period. 12 patients were diagnosed with non-infective asthma (mean age 52, M:F=5:7) and 17 with non infective COPD (mean age $76, \mathrm{M}: \mathrm{F}=5: 12$ ). The preponderance of female admissions has been noted in previous studies. ${ }^{2}$ Ash cloud formation occurred at day 26 with closure of Scottish airports at day 27, 45, 51 and 58. Ash production subsided day 63 . We observed a cluster of admissions from day 22 to day 37.

Conclusions The cluster of admissions associated with ash cloud presence suggests the possibility of a causative effect. Our study is however limited by the duration of data collection and the absence of a comparative data from previous years. 